\title{
Azacitidine induces demethylation of p16INK4a and inhibits growth in adult T-cell leukemia/lymphoma
}

\author{
KUMI UENOGAWA ${ }^{1}$, YOSHIHIRO HATTA ${ }^{1}$, NAOMICHI ARIMA ${ }^{2}$, SATOSHI HAYAKAWA ${ }^{3}$, \\ UMIHIKO SAWADA $^{1}$, SHIN AIZAWA ${ }^{4}$, TATSUO YAMAMOTO ${ }^{5}$ and JIN TAKEUCHI $^{1}$
}

\begin{abstract}
Departments of ${ }^{1}$ Hematology and Rheumatology, ${ }^{3}$ Microbiology, ${ }^{4}$ Functional Morphology and ${ }^{5}$ Obstetrics and Gynecology, Nihon University, School of Medicine, Itabashi-ku, Tokyo 173-8610; ${ }^{2}$ Division of Hematology and Immunology, Graduate School of Medical and Dental Sciences Kagoshima University, Kagoshima 890-8544, Japan
\end{abstract}

Received May 11, 2011; Accepted June 10, 2011

DOI: $10.3892 /$ ijmm.2011.756

\begin{abstract}
Adult T-cell leukemia/lymphoma (ATL) is one of the peripheral T-cell malignant neoplasms strongly associated with human T-cell leukemia virus type-I (HTLV-I). Although the viral transactivator protein Tax has been proposed to play a critical role in leukemogeneis, additional cellular events are required for the development of ATL. One of the genetic events of the disease is inactivation of tumor suppressor genes. The CDKN2A locus on chromosome 9p encodes 2 cell cycle regulatory proteins, p14ARF and p16INK4a, which share exon 2 using different reading frames. The p14ARF and p16INK4a genes have been implicated as tumor suppressor genes by their frequent mutation, deletion or promoter hypermethylation in a variety of human tumors. In this report, we describe the expression status of p14ARF and p16INK4a in 9 ATL cell lines (MT1, MT2, OKM3T, F6T, K3T, Oh13T, S1T, Su9T01 and HUT102). By reverse transcription polymerase chain reaction (RT-PCR), expression of p14ARF was not detected in one cell line (OKM3T), while expression of p16INK4a was not detected in 6 cell lines (OKM3T, MT1, MT2, Oh13T, S1T and Su9T01). In the OKM3T cell line, the shared exon 2 of the p14ARF/p16INK4a gene was deleted; however, the p16INK4a gene, was epigenetically inactivated in 5 other cells lines. In primary tumor cells obtained from ATL patients, p14ARF expression was absent in 6 of the 11 samples. We confirmed the methylation of the p16INK4a gene in MT1 and MT2 cells using the methylation-specific PCR (MSP) method. Treatment with $2.0 \mu \mathrm{M}$ of Azacitidine (AZA), a demethylating agent, for $72 \mathrm{~h}$ restored p16INK4a transcript expression and induced growth inhibition in MT2 cells. Our results demonstrate that p16INK4a is epigenetically silenced in ATL. AZA offers a potential new therapeutic approach to improve the poor outcomes associated with ATL.
\end{abstract}

Correspondence to: Dr Yoshihiro Hatta, Department of Hematology and Rheumatology, Nihon University, School of Medicine, 30-1 Oyaguchi, Itabashi-ku, Tokyo 173-8610, Japan

E-mail: hatta.yoshihiro@nihon-u.ac.jp

Key words: p14ARF, p16INK4a, methylation, Azacitidine

\section{Introduction}

Adult T-cell leukemia/lymphoma (ATL) is an aggressive, fatal malignancy of mature $\mathrm{CD} 4^{+} \mathrm{T}$ lymphocytes caused by human T-cell lymphotropic virus type I (HTLV-I) infection (1). ATL has been classified into four main subtypes (2). In the relatively indolent smoldering and chronic forms, median survival is 2 years or more. In the acute and lymphoma forms, median survival time is about 13 months (3). Although a pivotal oncoprotein of HTLV-I, Tax, is strongly associated with the development of ATL (4), precise mechanisms of tumorigenesis in ATL have not been well-defined. A long period of clinical latency precedes the development of ATL (5) and only a small percentage of HTLV-I-infected individuals develop this malignancy (6), indicating that additional genetic events probably are required to develop ATL after viral infection of the target $\mathrm{T}$ cells. Studies to date by others and ourselves have shown deletions or mutations of several tumor suppressor genes in the pathogenesis of ATL (7-10).

p16INK4a, one of the cyclin-dependent kinase inhibitors (CDKIs), was implicated as a tumor suppressor gene. The gene harboring the CDKN2A locus on chromosome 9p21 binds to CDK4 and thereby inhibits its kinase activities $(11,12)$, resulting in arrest of the cell cycle. The CDKN2A locus also generates another cell cycle-regulatory protein designated as alternative reading frame (ARF), which encodes a protein of $14 \mathrm{kDa}$ (p14ARF) (13). The p14ARF gene has a unique exon 1 (exon $1 \beta$ ), located approximately $20 \mathrm{~kb}$ centrometric to exon 1 of p16INK4a. Under the control of each promoter, exon $1 \beta$ and exon 1 splice into exon 2 in the CDKN2A locus, producing p14ARF and p16INK4a proteins, respectively $(13,14)$. Therefore, the p14ARF and p16INK4a genes share the same exon 2 . p14ARF interacts in vivo with the MDM2 protein, neutralizing MDM2-mediated degradation of p53 $(15,16)$. Inactivation of the p14ARF and p16INK4a results from homozygous deletion or promoter methylation (17-19). We have previously reported the homozygous deletion of p16INK4a in a significant portion of patietns with ATL (7). In addition, inactivation of p14ARF and p16INK4a by hypermethylation has been described in common neoplasms including T-cell lymphoma (20).

Azacitidine (AZA) has been administered as a new antineoplastic agent for myelodysplastic syndrome (MDS) with 
good outcome (21-24). The agent induces the demethylation of gene promoter via inhibition of DNA methyltransferase (DNMT) that methylates cytosine residues in eukaryotic DNA $(22,25)$.

Because prognosis of ATL is extremely poor, new treatment agents need to be identified. In this study, we investigated the inactivation status of p14ARF and p16INK4a in ATL cell lines as well as primary ATL cells obtained from patients with various clinical types of ATL. We demonstrate that AZA is a potential therapeutic candidate for ATL.

\section{Materials and methods}

Cells. Nine ATL cell lines, MT1, MT2, OKM3T, F6T, K3T, Oh13T, S1T, Su9T01 and HUT102 were analyzed. OKM3T was originally established by Miyamoto et al (26) and obtained from the Dainippon Sumitomo Pharmaceutical Co., Ltd. (Osaka, Japan). F6T, K3T, Oh13T, S1T and Su9T01 (27) were established in our institute. K562 was used as a negative control. Cell lines were maintained by serial passages in RPMI containing $10 \%$ heat-inactivated fetal calf serum (FCS), $100 \mathrm{U} / \mathrm{ml}$ penicillin and $100 \mathrm{U} / \mathrm{ml}$ streptomycin, and incubated in standard tissue culture incubators with $5 \% \mathrm{CO}_{2}-95 \%$ air at $37^{\circ} \mathrm{C}$. In addition to these cell lines, mononuclear cells were isolated from either peripheral blood samples from 10 leukemia type ATL patients (6 acute, 3 chronic and 1 undetermined) or from a lymph node sample of a lymphoma type ATL patient. All patients provided written informed consent.

DNA extraction and polymerase chain reaction (PCR) analysis. DNA was isolated with the Sepagene kit (Sanko Jun-yaku, Tokyo, Japan) according to the manufacturer's instructions. All samples were screened for exon 2 of p14ARF/ p16INK4a with PCR by our method (7). The primers p16-1S1 (5'-CTTCCTGGACACGCTGGTGGTGCTG-3') and p16-2A2 (5'-GTACAAATTCTCAGATCATCAGTCC-3') were used to obtain a 219-bp fragment of exon 2 of p14ARF/p16INK4a. The cycling conditions were one cycle of $15 \mathrm{~min}$ at $95^{\circ} \mathrm{C}, 36$ cycles of $60 \mathrm{sec}$ at $95^{\circ} \mathrm{C}, 30 \mathrm{sec}$ at $55^{\circ} \mathrm{C}, 120 \mathrm{sec}$ at $72^{\circ} \mathrm{C}$, and one cycle of $10 \mathrm{~min}$ at $72^{\circ} \mathrm{C}$. The PCR was repeated $\geq 2$ times.

RNA extraction and reverse transcription polymerase chain reaction (RT-PCR) analysis. Total-RNA was extracted with a single-step method using RNAzol reagent (Sawady, Tokyo, Japan). RT reactions were performed using a First-Strand cDNA Synthesis kit (Amersham Pharmacia Biotec, Little Chalfont, Buckinghamshire, UK) according to the manufacturer's protocol. Products were then used as templates in PCR analysis. The mRNA transcription of the p14ARF and p16INK4a genes was evaluated by RT-PCR. The primer pairs specific for these genes were as follows; p14ARF sense, 5'-GGTTTTCGTGGTTCACATCCCGCG-3' and antisense, 5'-CAGGAAGCCCTCCCGGGCAGC-3'; p16INK4a sense, 5'-TTCGGCTGACTGGCTGGCCA-3' and antisense, 5'-AGC TCCTCAGCCAGGTCCAC-3'. The length of the p14ARF and p16INK4a PCR products was 254 and $330 \mathrm{bp}$, respectively. Efficacy of reverse transcription was controlled in each sample by PCR amplification of $\beta$-actin using the following primer pair: sense, 5'-TACATGGGTGGGGTGTTGAA-3' and antisense, 5'-AAGAGAGGCATCCTCACCCT-3'.
Methylation-specific PCR (MSP). To determine the methylation status at the $5^{\prime} \mathrm{CpG}$ island in the p16INK4a promoter region, we performed MSP. Bisulfite converts unmethylated cytosine residues to uracil, but methylated cytosines remain nonreactive. PCR amplifies uracil as thymine while methylated cytosines are only amplified as cytosines. MSP distinguishes unmethylated from methylated alleles in a given gene based on sequence changes after bisulfite treatment of DNA using primers designed for either methylated or unmethylated DNA (28). The CpGenome ${ }^{\mathrm{TM}}$ DNA Modification kit (Chemicon International, Inc., Temecula, CA) was used for MSP, as recommended by the supplier (29). Genomic DNA was treated with sodium bisulfite. PCR amplification was performed using p16INK4a promoter gene fragment-specific primers for either methylated or unmethylated DNA (CpG WIZ ${ }^{\mathrm{TM}}$ Amplification kit, Chemicon International, Inc.) (30). The unmethylated p16INK4a was amplified with a primer pair 5'-TTTTTGGT GTTAAAGGGTGGTGTAGT-3' and 5'-CACAAAAAC CCTCACTCACAACAA-3', which yielded a fragment of $132 \mathrm{bp}$. The primers for methylated p16INK4a were 5'-GTG TTAAAGGGCGGCGTAGC-3' and 5'-AAAACCCTCAC TCGCGACGA-3', which yielded a PCR product of $122 \mathrm{bp}$. Universal methylation DNA CpGenome ${ }^{\mathrm{TM}}$ (Chemicon International, Inc.) was used as a control for methylated DNA. PCR-amplified products were separated by electrophoresis on $2 \%$ agarose gel and visualized by ethidium bromide staining under UV wave.

Treatment with AZA. To determine the optimal dose of AZA (Sigma, St. Louis, MO), MT2 cells were treated with increasing doses of AZA. MT2 cells at a concentration of $1 \times 10^{5} / \mathrm{ml}$ were treated with $0.5,1.0$ or $2.0 \mu \mathrm{M}$ of AZA. After cells were cultured for $72 \mathrm{~h}$ with AZA, RNA was harvested. The expression of p16INK4a mRNA was detected by RT-PCR.

Growth inhibition with AZA on MT2 cells. MT2 cells at a concentration of $1 \times 10^{5} / \mathrm{ml}$ were treated with $2.0 \mu \mathrm{M}$ of AZA. The number of viable cells was counted on days 2, 3, 4 and 5 using the trypan blue dye exclusion procedure. All experiments were repeated 3 times.

\section{Results}

Deletion of the p14ARF and p16INK4a gene. Nine cell lines were examined for deletions of the exon 2 of p14ARF/p16INK4a. The K562 cell line served as a negative control. The gene was deleted in only one cell line, OKM3T (Fig. 1).

Expression of p14ARF. Expression of p14ARF mRNA was examined in 9 cell lines by RT-PCR. Only OKM3T did not express p14ARF mRNA (Fig. 2) due to deletion of the gene. The p14ARF mRNA was also amplified for primary ATL samples. Of the 11 ATL samples analyzed, p14ARF was not expressed in 6 (4 acute, 1 chronic and 1 undetermined), while 5 samples expressed p14ARF (2 acute, 1 lymphoma and 2 chronic) (Fig. 3).

Expression of p16INK4a. Among 9 cell lines, the OKM3T cell line in which exon 2 of the p16INK4a gene was deleted did not express p16INK4a. An additional 5 cell lines (MT1, MT2, 


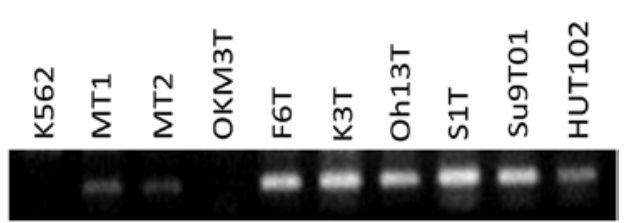

Figure 1. Deletion of the p14ARF and p16INK4a exon 2 gene in ATL cell lines. Among the 9 cell lines, the shared exon 2 of the p14ARF/p16INK4a gene was deleted in the OKM3T cell line. K562 was served as a negative control.

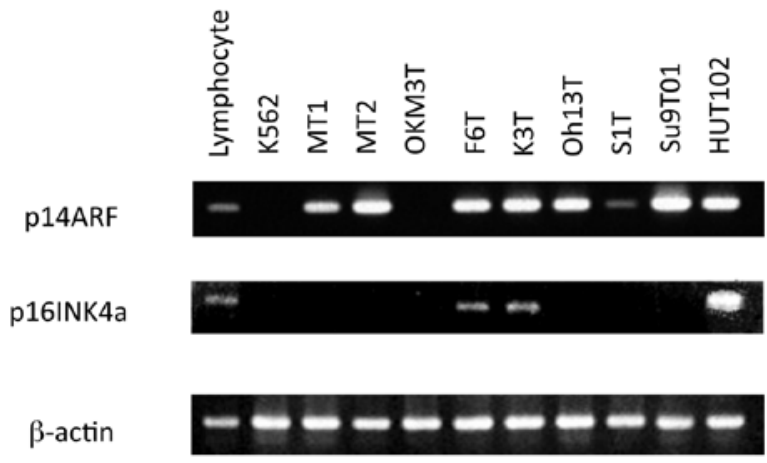

Figure 2. Expression of p14ARF and p16INK4a mRNA in ATL cell lines by RT-PCR. Among the 9 cell lines, the OKM3T cell line in which the shared p14ARF/p16INK4a exon 2 was deleted did not express either p14ARF or p16INK4a. Five other cell lines (MT, MT2, Oh13T, S1T and Su9T01) in which the p14ARF/p16INK4a exon 2 was not deleted, lacked expression of p16INK4a.

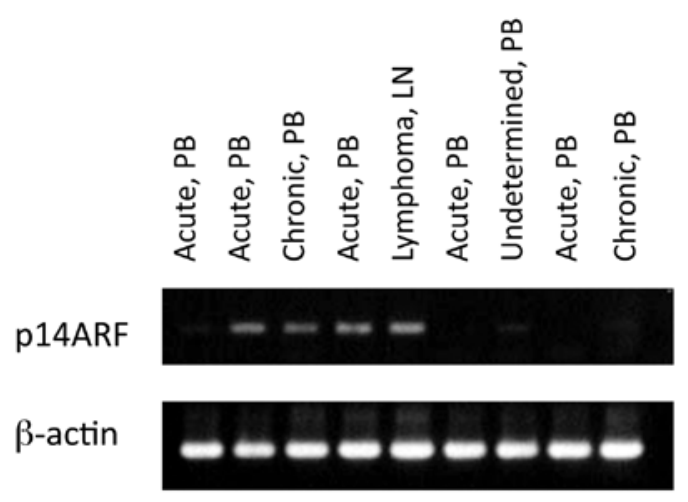

Figure 3. Expression of p14ARF in primary ATL samples. Representative cases are shown. Acute, PB, sample from peripheral blood in acute ATL; chronic, PB, sample from peripheral blood in chronic ATL; lymphoma, LN, sample from lymph node in lymphoma ATL; undetermined, PB, sample from peripheral blood in undetermined type ATL.

Oh13T, S1T and Su9T01) which had the p14ARF/p16INK4a exon 2 lacked expression of p16INK4a (Fig. 2).

Analysis of methylation of the pl6INK4a gene. Because MT1 and MT2 did not express p16INK4a, the presence of methylation in the p16INK4a promoter region gene was assessed in the MT1 and MT2 cell lines using MSP. DNA obtained from lymphocytes from healthy volunteers was used as an unmethylated control. The K562 cell line served as a negative control. Both MT1 and MT2 cell lines displayed a band only when amplified with primers for methylated and not for unmethylated DNA (Fig. 4).

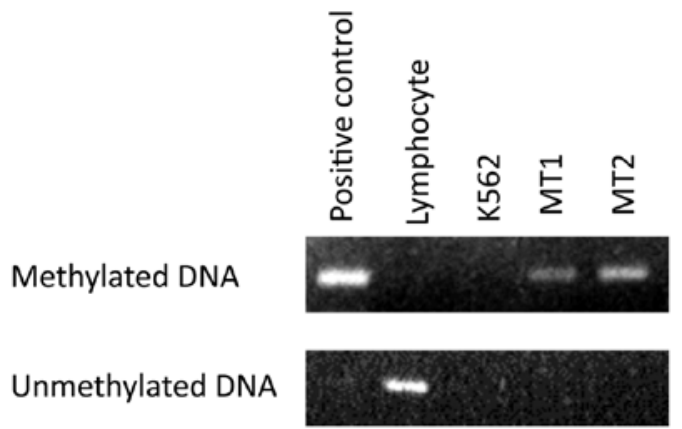

Figure 4. Methylation of the p16INK4a gene in MT1 and MT2 by methylation specific PCR (MSP). Both MT1 and MT2 cell lines displayed a band only when amplified with primers for methlyated DNA but not unmethylated DNA. DNA obtained from lymphocytes from healthy volunteers was used as an unmethylated control. The K562 cell line served as a negative control.

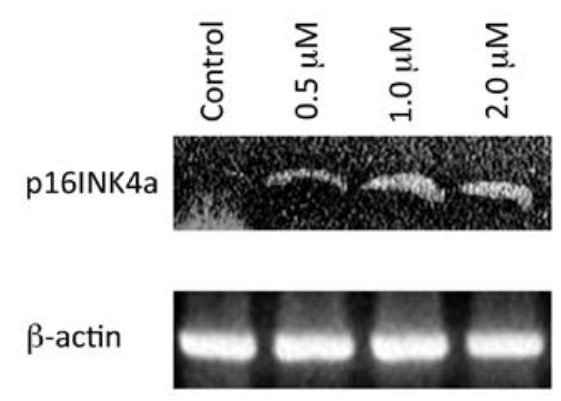

Figure 5. Restoration of p16INK4a gene expression by Azacitidine (AZA). AZA induced the demethylation of the p16INK4a gene promoter. Substantial demethylation of p16INK4a was observed after $72 \mathrm{~h}$ of treatment with $0.5 \mu \mathrm{M}$ AZA. With higher doses of AZA $(1.0$ or $2.0 \mu \mathrm{M})$, the expression of p16INK4a mRNA was clearly up-regulated.

Restoration of pl6INK4a gene expression by AZA. AZAinduced the demethylation of the p16INK4a gene promoter. Substantial demethylation of p16INK4a was observed after $72 \mathrm{~h}$ of treatment with $0.5 \mu \mathrm{M}$ AZA. With higher doses of AZA (1.0 or $2.0 \mu \mathrm{M})$, the expression of p16INK4a mRNA was clearly up-regulated (Fig. 5).

AZA induces growth inhibition of MT2 cells. MT2 cells at a concentration of $1 \times 10^{5} / \mathrm{ml}$ were treated with $2.0 \mu \mathrm{M}$ of AZA. Growth of $2.0 \mu \mathrm{M}$-treated cells was inhibited compared with the control, although the difference was marginal. On Day 3, viable cell numbers in the control and 2.0 $\mu \mathrm{M}$ AZA treated MT2 cells were 4.8 and $4.1 \times 10^{6} / \mathrm{ml}$, respectively. After obtaining maximum cell growth, viable cells decreased in both groups (Fig. 6).

\section{Discussion}

ATL is triggered by infection of the human T-cell leukemia virus type I (HTLV-I) (1), with its pivotal oncoprotein Tax being stongly associated with the development of ATL (4). However, expression of Tax disappears in most ATL cells, suggesting that alternative mechanisms may be involved in the development of ATL. A statistical analysis revealed that five independent genetic events are probably required to develop ATL after viral infection of the target T cells (31). 


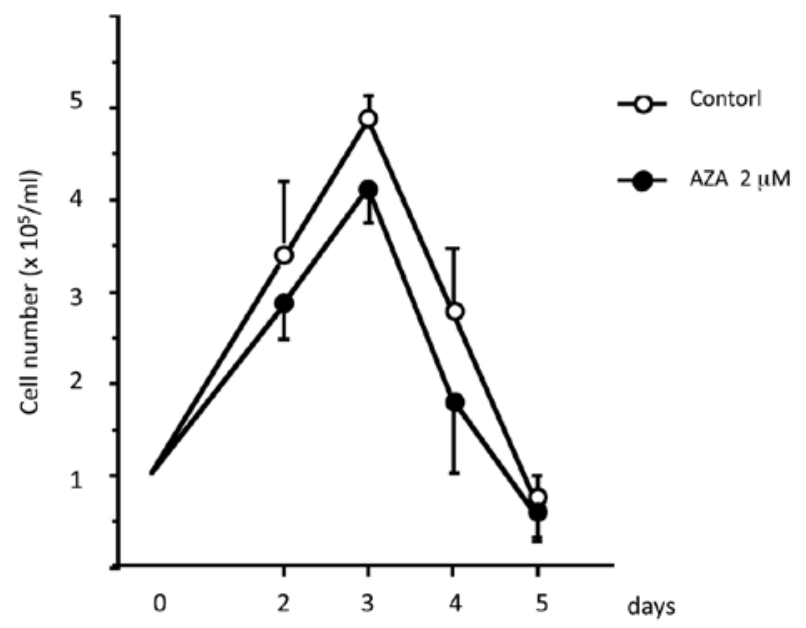

Figure 6. Azacitidine (AZA) induces growth inhibition of MT2 cells. MT2 cells at a concentration of $1 \times 10^{5} / \mathrm{ml}$ were treated with $2.0 \mu \mathrm{M}$ of AZA. Growth of $2.0 \mu \mathrm{M}$ treated cells was inhibited compared with the control, although the difference was marginal. On Day 3, viable cell numbers in control and $2.0 \mu \mathrm{M}$ AZA-treated MT2 cells were $4.8 \times 10^{6} / \mathrm{ml}$, and $4.1 \times 10^{6} / \mathrm{ml}$, respectively. After obtaining maximum cell growth, viable cells decreased in both groups.

p16INK4a, one of the CDKIs, resides in the CDKN2A locus on chromosome 9p. p16INK4a inhibits the catalytic activity of the CDK4/cyclin D complexes and blocks G1 to S transition in the cells $(11,12)$. The CDKN2A locus also generates another cell cycle-regulatory protein, p14ARF $(13,14)$. The human p14ARF protein causes arrest in the cell-cycle progression with an accumulation of cells in both G1 and G2/M, through binding to MDM2, which interferes with p53-MDM2 complex formation and proteasome degradation $(32,33)$. Data suggest that both p14ARF and p16INK4A act as tumor suppressors whose inactivation contributes to the development of human tumors.

The homozygous deletion of the p16INK4a gene has been detected at a very high rate in many types of solid tumors as well as leukemias $(34,35)$ especially in T-ALL $(36,37)$. In ATL, we have shown that several tumor suppressor genes including p16INK4a, p18INK4c, and Rb were altered $(7,10,36,37)$. The p16INK4a gene was frequently deleted in ATL (7). Furthermore, methylation of the 5' CpG island in the p16INK4a gene is associated with transcriptional silencing of the gene in many neoplasms including leukemias and lymphomas (38).

We screened the expression of p14ARF and p16INK4a in ATL cell lines. One (OKM3T) and 6 (MT1, MT2, OKM3T, Oh13T, S1T and Su9T01) of the 9 cell lines did not express p14ARF and p16INK4a mRNA, respectively. Absence of p16INK4a mRNA in the OKM3T cell line was due to deletion of the shared exon 2 gene of p14ARF/p16INK4a, while in the remaining 5 cell lines, it was due to gene silencing. Although we did not examine the genetic status of exon 1 of p16INK4a, deletion of the gene is unlikely, because, in our previous study, exons 1 and 2 of p16INK4a were homozygously deleted simultaneously in all ATL samples (7).

In our study, most of ATL cell lines expressed p14ARF mRNA, while 6 of 11 primary samples lacked expression of p14ARF. Esteller et al reported that p14ARF was epigenetically inactivated by hypermethylation in colorectal cancer cell lines as well as primary colorectal cancer samples (30). p14ARF genomic alterations are found in T-cell acute lymphocytic leukemias (39). Inactivation, either by deletion or methylation, of p14ARF may account for developing ATL.

DNA hypermethylation is the main epigenetic modification in tumorigenesis (40). Cytosine analogues such as 5-Aza-2'deoxycytidine and AZA can induce expression of several tumor suppressor genes with unmethylated $\mathrm{CpGs}$ in malignant cells by inhibiting DNMTs $(41,42)$. In recent reports, treatment with low-dose AZA was very encouraging in older patients with MDS and AML (24). Although the target genes of AZA in MDS have not been well-defined, one of the candidates is the p15INK4b gene that shares a great deal of nucleotide sequence homology with p16INK4a and is localized $25 \mathrm{~kb}$ upstream of the p16 INK4a locus on chromosome 9p21.

Nosaka et al reported the epigenetic inactivation of p16INK4a in ATL and suggested that methylation was a critical factor in disease progression (43). We demonstrate the demethylation in p16INK4a and induction of growth inhibition of the ATL cell line, MT2, with AZA. The expression of p16INK4a mRNA was up-regulated by treatment with $0.5 \mu \mathrm{M}$ of AZA for $72 \mathrm{~h}$. AZA showed inhibition of cell growth of ATL cell lines. Because no obvious toxicity of AZA was observed in phase 3 clinical trials for patients with high-risk MDS (21), our studies suggest a therapeutic approach for ATL. Although single administration of AZA is not sufficient to eradicate ATL cells, concomitant use with other anti-tumor agents such as thalidomide may be more effective as has been reported in MDS (23). This is particularly interesting because ATL cells are highly resistant to the induction of apoptosis and there is still no beneficial treatment other than allogeneic hematopoietic stem cell transplantation for this acute and fatal disease.

In conclusion, p16INK4a is epigenetically inactivated in ATL. AZA should be further investigated as a novel therapeutic agent for the management of ATL.

\section{Acknowledgements}

We thank Mr. Kanji Miyamoto for providing cell lines for this study. Also, a thank you is due to Ms. Yuko Enomoto for technical assistance. This study was supported by a grant from the Nihon University Alumni and Strategic Research Base Development Program for Private Universities subsidized by MEXT, Japan.

\section{References}

1. Yoshida M, Miyoshi I and Hinuma Y: Isolation and characterization of retrovirus from cell lines of human adult T-cell leukemia and its implication in the disease. Proc Natl Acad Sci USA 79: 2031-2035, 1982.

2. Shimoyama M: Diagnostic criteria and classification of clinical subtypes of adult T-cell leukemia-lymphoma. A report from the Lymphoma Study Group (1984-87). Br J Haematol 79: 428-437, 1991.

3. Yamada Y, Tomonaga M, Fukuda H, Hanada S, Utsunomiya A, Tara A, Sano M, Ikeda S, Takatsuki K, Kozuru M, Araki K, Kawano F, Niimi M, Tobinai K, Hotta T and Shimoyama M: A new G-CSF-supported combination chemotherapy: LSG15, for adult T-cell leukaemia-lymphoma: Japan Clinical Oncology Group Study 9303. Br J Haematol 113: 375-382, 2001.

4. Kiyokawa T, Seiki M, Imagawa K, Shimizu F and Yoshida M: Identification of a protein ( $\mathrm{p} 40 \mathrm{x})$ encoded by a unique sequence $\mathrm{pX}$ of a human T-cell leukemia virus type I. Gann 75: 747-751, 1984. 
5. Tajima K: The fourth nationwide study of adult T-cell leukemia/ lymphoma (ATL) in Japan: estimates of risk of ATL and its geographical and clinical features. The T- and B-cell Malignancy Study Group. Int J Cancer 45: 237-243, 1990.

6. Tokudome S, Tokunaga O, Shimamoto Y, Miyamoto Y, Sumida I, Kikuchi M, Takeshita M, Ikeda T, Fujiwara K, Yoshihara M, Yanagawa T and Nishizumi M: Incidence of adult T-cell leukemia/ lymphoma among human T-lymphotropic virus type 1 carriers in Saga, Japan. Cancer Res 49: 226-228, 1989.

7. Hatta Y, Hirama T, Miller CW, Yamada Y, Tomonaga M and Koeffler HP: Homozygous deletions of the p15 (MTS2) and p16 (CDKN2/MTS1) genes in adult T-cell leukemia. Blood 85: 2699-2704, 1995.

8. Hatta Y, Yamada M, Tomonaga M and Koeffler HP: Extensive analysis of the retinoblastoma gene in adult $\mathrm{T}$ cell leukemia/ lymphoma (ATL). Leukemia 11: 984-989, 1997.

9. Hatta Y, Spirin K, Tasaka T, Morosetti R, Said JW, Yamada Y, Tomonaga M and Koeffler HP: Analysis of p18INK4C in adult T-cell leukaemia and non-Hodgkin's lymphoma. Br J Haematol 99: 665-667 1997

10. Fujiwara H, Arima N, Hashimoto-Tamaoki T, Matsushita $\mathrm{K}$, Ohtsubo $\mathrm{H}$, Arimura K, Hidaka S and Tei C: Alteration of p16 (CDKN2) gene is associated with interleukin-2-induced tumor cell growth in adult T-cell leukemia. Exp Hematol 27: 1004-1009, 1999.

11. Kamb A, Shattuck-Eidens D, Eeles R, Liu Q, Gruis NA, Ding W, Hussey C, Tran T, Miki Y, Weaver-Feldhaus J, McClure M, Aitken JF, Anderson DE, Bergman W, Frants R, Goldgar DE, Green A, MacLennan R, Martin NG, Meyer LJ, Youl P, Zone JJ, Skolnick MH and Cannon-Albright LA: Analysis of the p16 gene (CDKN2) as a candidate for the chromosome 9p melanoma susceptibility locus. Nat Genet 8: 23-26, 1994.

12. Tam SW, Shay JW and Pagano M: Differential expression and cell cycle regulation of the cyclin-dependent kinase 4 inhibitor p16Ink4. Cancer Res 54: 5816-5820, 1994.

13. Quelle DE, Zindy F, Ashmun RA and Sherr CJ: Alternative reading frames of the INK4a tumor suppressor gene encode two unrelated proteins capable of inducing cell cycle arrest. Cell 83: 993-1000, 1995

14. Stone S, Jiang P, Dayananth P, Tavtigian SV, Katcher H, Parry D, Peters $\mathrm{G}$ and Kamb A: Complex structure and regulation of the P16 (MTS1) locus. Cancer Res 55: 2988-2994, 1995.

15. Zhang Y, Xiong Y and Yarbrough WG: ARF promotes MDM2 degradation and stabilizes p53: ARF-INK4a locus deletion impairs both the $\mathrm{Rb}$ and $\mathrm{p} 53$ tumor suppression pathways. Cell 92: 725-734, 1998.

16 Kamijo T, Weber JD, Zambetti G, Zindy F, Roussel MF and Sherr CJ: Functional and physical interactions of the ARF tumor suppressor with p53 and Mdm2. Proc Natl Acad Sci USA 95: $8292-8297,1998$

17. Merlo A, Herman JG, Mao L, Lee DJ, Gabrielson E, Burger PC Baylin SB and Sidransky D: 5' $\mathrm{CpG}$ island methylation is associated with transcriptional silencing of the tumour suppressor $\mathrm{p} 16$ / CDKN2/MTS1 in human cancers. Nat Med 1: 686-692, 1995.

18. Endo M, Kobayashi C, Setsu N, Takahashi Y, Kohashi K, Yamamoto H, Tamiya S, Matsuda S, Iwamoto Y, Tsuneyoshi M and Oda Y: Prognostic significance of p14ARF, p15INK4b and p16INK4a inactivation in malignant peripheral nerve sheath tumors. Clin Cancer Res 17: 3771-3782, 2011.

19. Jardin F, Jais JP, Molina TJ,Parmentier F, Picquenot JM,Ruminy $P$, Tilly H, Bastard C, Salles GA, Feugier P, Thieblemont C, Gisselbrecht C, de Reynies A, Coiffier B, Haioun C and Leroy K: Diffuse large B-cell lymphomas with CDKN2A deletion have a distinct gene expression signature and a poor prognosis under R-CHOP treatment: a GELA study. Blood 116: 1092-1104, 2010.

20. Matsushita C, Yang Y, Takeuchi S, Matsushita M, Van Dongen JJ Szczepanski T, Bartram CR, Seo H, Koeffler HP and Taguchi H: Aberrant methylation in promoter-associated $\mathrm{CpG}$ islands of multiple genes in relapsed childhood acute lymphoblastic leukemia. Oncol Rep 12: 97-99, 2004.

21. Silverman LR, Demakos EP, Peterson BL, Kornblith AB, Holland JC, Odchimar-Reissig R, Stone RM, Nelson D, Powell BL, DeCastro CM, Ellerton J, Larson RA, Schiffer CA and Holland JF: Randomized controlled trial of azacitidine in patients with the myelodysplastic syndrome: a study of the Cancer and Leukemia Group B. J Clin Oncol 20: 2429-2440, 2002.

22. Silverman LR, McKenzie DR, Peterson BL, Holland JF, Backstrom JT, Beach CL and Larson RA; Cancer and Leukemia Group B: Further analysis of trials with azacitidine in patients with myelodysplastic syndrome: studies 8421,8921 , and 9221 by the Cancer and Leukemia Group B. J Clin Oncol 24: 3895-3903, 2006.
23. Raza A, Mehdi M, Mumtaz M, Ali F, Lascher S and Galili N: Combination of 5-azacytidine and thalidomide for the treatment of myelodysplastic syndromes and acute myeloid leukemia. Cancer 113: 1596-1604, 2008

24. Silverman LR,Fenaux P, Mufti GJ, Santini V,Hellström-Lindberg E, Gattermann N, Sanz G, List AF, Gore SD and Seymour JF: Continued azacitidine therapy beyond time of first response improves quality of response in patients with higher-risk myelodysplastic syndromes. Cancer: Jan 10, 2011 (Epub ahead of print).

25. Christman JK: 5-Azacytidine and 5-aza-2'-deoxycytidine as inhibitors of DNA methylation: mechanistic studies and their implications for cancer therapy. Oncogene 21: 5483-5495, 2002.

26. Miyamoto K, Tomita N, Ishii A, Nishizaki T and Togawa A Establishment and characterization of adult T-cell leukemia viruscontaining B-cell lines derived from peripheral blood of adult T-cell leukemia patients. Gann 75: 655-659, 1984.

27. Arima N, Molitor JM, Smith MR, Kim JH, Daitoku Y and Greene W: Human T-cell leukemia virus type I Tax induces expression of the Rel-related family of $\mathrm{kB}$ enhancer-binding proteins: evidence for a pre-translational component of regulation. J Virol 65: 6892-6899, 1991.

28. Herman JG, Graff JR, Myöhänen S, Nelkin BD and Baylin SB: Methylation-specific PCR: a novel PCR assay for methylation status of CpG islands. Proc Natl Acad Sci USA 93: 9821-9826, 1996.

29. Tsujie M, Yamamoto H, Tomita N, Sugita Y, Ohue M, Sakita I, Tamaki Y, Sekimoto M, Doki Y, Inoue M, Matsuura N, Monden T, Shiozaki $\mathrm{H}$ and Monden M: Expression of tumor suppressor gene p16(INK4) products in primary gastric cancer. Oncology 58: 126-136, 2000.

30. Esteller M, Tortola S, Toyota M, Capella G, Peinado MA, Baylin SB and Herman JG: Hypermethylation-associated inactivation of p14 (ARF) is independent of p16 (INK4a) methylation and p53 mutational status. Cancer Res 60: 129-133, 2000.

31. Okamoto T, Ohno Y, Tsugane S, Watanabe S, Shimoyama M, Tajima K, Miwa M and Shimotohno K: Multi-step carcinogenesis model for adult T-cell leukemia. Jpn J Cancer Res 80: 191-195, 1989.

32. Haupt Y, Maya R, Kazaz A and Oren M: Mdm2 promotes the rapid degradation of p53. Nature 387: 296-299, 1997.

33. Kubbutat MH, Jones SN and Vousden KH: Regulation of p53 stability by Mdm2. Nature 387: 299-303, 1997.

34. Miller CW, Aslo A, Campbell MJ, Kawamata N, Lampkin BC and Koeffler HP: Alterations of the p15, p16, and p18 genes in osteosarcoma. Cancer Genet Cytogenet 86: 136-142, 1996.

35. Miller CW and Koeffler CW: Cyclin-dependent kinase inhibitors in human neoplasms. Leukemia 11 (Suppl 3): S370-S371, 1997.

36. Hebert J, Cayuela JM, Berkeley J and Sigaux F: Candidate tumorsuppressor genes MTS1 (p16INK4A) and MTS2 (p15INK4B) display frequent homozygous deletions in primary cells from T- but not from B-cell lineage acute lymphoblastic leukemias. Blood 84: 4038-4044, 1994.

37. Ohnishi H, Kawamura M, Ida K, Sheng XM, Hanada R, Nobori T, Yamamori S and Hayashi Y. Homozygous deletions of p16/MTS1 gene are frequent but mutations are infrequent in childhood T-cell acute lymphoblastic leukemia. Blood 86: 1269-1275, 1995.

38. Herman JH, Civin CI, Issa JJ, Collector MI, Sharkis SJ and Baylin SB: Distinct patterns of inactivation of p15INK4B and p16INK4A characterize the major types of hematological malignancies. Cancer Res 57: 837-841, 1997.

39. Robertson KD and Jones PA: The human ARF cell cycle regulatory gene promoter is a $\mathrm{CpG}$ island which can be silenced by DNA methylation and down-regulated by wild-type p53. Mol Cell Biol 18: 6457-6473, 1998.

40. Egger G, Liang G, Aparicio A and Jones PA: Epigenetics in human disease and prospects for epigenetic therapy. Nature 429: 457-463, 2004.

41. Daskalakis M, Nguyen TT, Nguyen C, Guldberg P, Köhler G, Wijermans P, Jones PA and Lübbert M: Demethylation of a hypermethylated p16/INK4B gene in patients with myelodysplastic syndrome by 5 -Aza-2'-deoxycytidine (decitabine) treatment. Blood 100: 2957-2964, 2002.

42. Zhu WG, Dai Z, Ding H, Srinivasan K, Hall J, Duan W, Villalona-Caero MA, Plass C and Otterson GA: Increased expression of unmethylated CDKN2D by 5 -aza-2'-deoxycytidine in human lung cancer cells. Oncogene 20: 7787-7796, 2001.

43. Nosaka K, Maeda M, Tamiya S, Sakai T, Mitsuya H and Matsuoka M: Increasing methylation of the CDKN2 gene is associated with the progression of adult T-cell leukemia. Cancer Res 60: 1043-1048, 2000. 